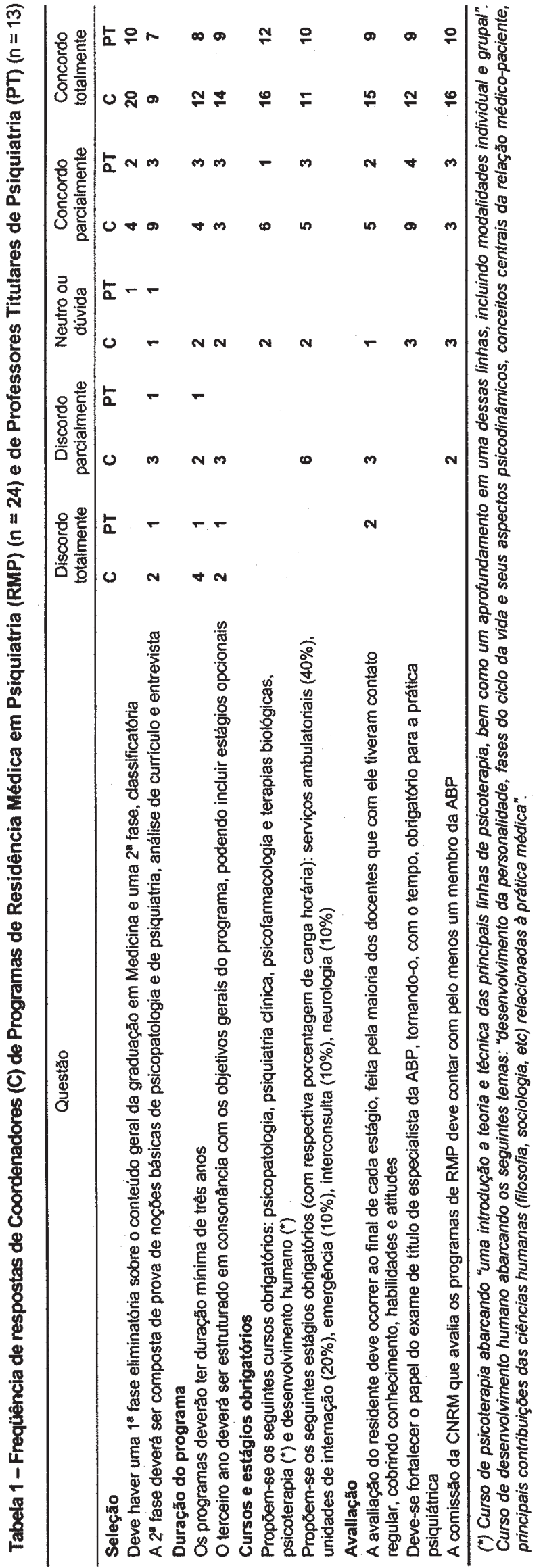

\section{Expansão do Programa Saúde da Família (PSF) e identificação de problemas relacionados ao uso de álcool no Brasil}

Expansion of the Family Health Program (FHP) and identification of alcohol-related problems in Brazil

Em 1994, o Ministério da Saúde do Brasil implantou o Programa Saúde da Família (PSF) com propósito de "reorganizar a prática da atenção à saúde em novas bases e substituir 0 modelo tradicional, levando a saúde para mais perto da família e, com isso, melhorar a qualidade de vida dos brasileiros". ${ }^{1}$ A estratégia do PSF prioriza as ações de vigilância, prevenção, promoção e recuperação da saúde, de forma integral e contínua.

Os problemas relacionados ao uso de álcool vêm sendo reconhecidos como relevantes agravos à saúde pública no Brasil, relacionando-se a acidentes de trânsito e a impactos relevantes nos anos potenciais de vida perdidos por doença ou morte precoce..$^{2-3}$

Reconhecendo a potencialidade do PSF em tornar-se uma importante estratégia para abordagem de problemas na área de saúde mental, ${ }^{4}$ o presente trabalho apresenta dados sobre a relação entre a expansão da cobertura do PSF na população com mais de 15 anos, no período de 1998 e 2004, e sua relação com a identificação nesta população de pessoas com "alcoolismo", utilizando o Sistema de Informações da Atenção Básica do Sistema Único de Saúde (SIAB/SUS).

Observa-se um incremento progressivo no número absoluto de pessoas cadastradas no PSF ao longo dos anos avaliados (Tabela 1). Considerando os extremos do período, o número passou de 2.058.054 para 48.364.457, havendo aumento superior a 23 vezes. Verificou-se que, no mesmo período, houve um aumento superior a 13 vezes no número de pessoas cadastradas com "alcoolismo", elevando-se de 28.821, em 1998, para 398.165, em 2004. Desta forma, verificou-se um declínio progressivo no percentual da população cadastrada no PSF identificada com "alcoolismo", passando de 1,4\%, em 1998, para cerca de 0,82\% em 2004; portanto uma redução em torno de $41,43 \%$. A redução do percentual de pessoas cadastradas com "alcoolismo" se correlaciona estatisticamente com 0 aumento da população cadastrada ( $p=0,001$, $r=-0,985, n=7$, Teste de Pearson).

Inicialmente, questiona-se a utilização da categoria "alcoolismo" no SIAB/SUS, visto que esta sequer faz parte da nomenclatura de doenças adotadas no Brasil, o que dificulta compreender qual dimensão do uso problemático de álcool está sendo registrada. A expansão da cobertura (evidenciada pelo número de pessoas cadastradas) veio acompanhada de uma redução na identificação das pessoas com "alcoolismo" (redução do percentual de cadastrados com "alcoolismo"), apontando para diminuição da capacidade de vigilância em saúde. Considera-se improvável que esta redução esteja associada à atuação do PSF junto à população, uma vez que, embora as ações na área de álcool e drogas tenham sido apontadas como essenciais, estas não foram efetivamente implantadas no âmbito do PSF. ${ }^{4}$ Por outro lado, pode-se considerar esta identificação como baixa em todos os anos investigados, se compararmos com dados nacionais que apontam para uma prevalência da dependência ao álcool em torno de $11,2 \%$ na população geral do país. ${ }^{5}$ 
Por fim, aponta-se para a necessidade de estudos prospectivos que busquem minimizar os possíveis vieses associados ao uso de fontes secundárias, bem como a premência de uma política nacional que possa capacitar, oferecer educação permanente e supervisão na temática de problemas relacionados ao uso de álcool para os profissionais que atuam no PSF.

Maximiliano Loiola Ponte de Souza Sociodiversidade em Saúde, Centro de Pesquisa Leônidas \& Maria Deane, Fundação Oswaldo Cruz, Manaus (AM), Brasil

Tabela 1 - 0 incremento da cobertura do Programa Saúde da Família (PSF) correlaciona-se com a diminuição na identificação de pessoas com "alcoolismo" na população com idade igual ou superior a 15 anos, no período de 1998-2004

\begin{tabular}{cccc}
\hline & $\begin{array}{c}\text { Número de pessoas com 15 } \\
\text { anos ou mais cadastradas no } \\
\text { PSF }\end{array}$ & $\begin{array}{c}\text { \% de pessoas com 15 anos } \\
\text { ou mais cadastradas no PSF } \\
\text { com "alcoolismo" }\end{array}$ \\
\cline { 2 - 3 } & Total & Com “alcoolismo" & \\
\hline $\mathbf{1 9 9 8}$ & 2.058 .054 & 28.821 & 1,400401 \\
$\mathbf{1 9 9 9}$ & 5.905 .101 & 77.936 & 1,319808 \\
$\mathbf{2 0 0 0}$ & 15.682 .824 & 178.985 & 1,14128 \\
$\mathbf{2 0 0 1}$ & 26.230 .097 & 267.412 & 1,019485 \\
$\mathbf{2 0 0 2}$ & 35.101 .354 & 344.471 & 0,981361 \\
$\mathbf{2 0 0 3}$ & 41.772 .289 & 377.195 & 0,902979 \\
$\mathbf{2 0 0 4}$ & 48.364 .457 & 398.165 & 0,82326 \\
\hline
\end{tabular}

$p=0,001, r=-0,985, n=7$, Teste de Pearson

Fonte: Adaptado do Sistema de Informação da Atenção Básica do Sistema Único de Saúde (SIAB/SUS)

Financiamento: Inexistente

Conflito de interesses: Inexistente

Referências

1. Brasil. Ministério da Saúde. Saúde da Família: uma estratégia para a reorientação do modelo assistencial. $2^{a}$ ed. Brasília: Ministério da Saúde/Secretaria de Assistência à Saúde/Coordenação de Saúde da Comunidade; 1998.

2. Melcop AG. Impacto do uso de álcool e outras vítimas de acidentes de trânsito. Brasília: ABDETRAN; 1997.

3. Meloni JN, Laranjeira R. Custo social e de saúde do consumo de álcool. Rev Bras Psiquiatr. 2004;26(Supl I):7-10.

4. Marques ACPR, Furtado EF. Intervenções breves para problemas relacionados ao álcool. Rev Bras Psiquiatr. 2004;26(Supl I):28-32.

5. Carlini EA, Galduróz JCF, Noto AR, Nappo SA: CEBRID - Centro Brasileiro de Informações sobre Drogas. I Levantamento Domiciliar sobre o Uso de Drogas no Brasil - 2001. São Paulo: Universidade Federal de São Paulo, CEBRID/SENAD; 2002. p. 480.

\section{Esquizofrenia e distorção da imagem corporal: considerações nosológicas}

Schizophrenia and body image distortion: nosological considerations

\section{Sr. Editor,}

Relatos de pacientes esquizofrênicos apresentando delírios de cunho somático e distorções da imagem corporal são encontrados desde o início do século XX, tendo sido descritos, inclusive, por Eugen Bleuler. ${ }^{1}$ O termo "esquizofrenia cenestopática" foi proposto por Huber, em 1957, como um subtipo daquela doença, ${ }^{2}$ caracterizado por queixas corporais predominantes e contínuas. Esta denominação não está incluída nas modernas classificações psiquiátricas (CID-10 e DSM-IV-TR), tendendo a desaparecer da nosologia psiquiátrica.

Neste trabalho, descrevemos o caso de uma paciente do sexo feminino, 31 anos, solteira, sem filhos, sem profissão, com oito anos de escolaridade. Vivia com a mãe e o irmão (este com diagnóstico de esquizofrenia). Não apresentava antecedente pessoal de transtorno psiquiátrico. Após seis meses de admissão em nosso serviço, passou a evoluir com ideação delirante persecutória (acreditava que pessoas planejavam matá-la ou prejudicar sua saúde), reforçada por vozes alucinatórias que dialogavam com a paciente e referiam-se à mesma em terceira pessoa. Paralelamente, iniciou comportamento caracterizado por ingesta, em grande quantidade, de alimentos de alto valor calórico. Fazia três refeições básicas com episódios de hiperingesta entre as mesmas, por vezes ingerindo 3.000 a 5.000 calorias ao dia. Por ocasião da admissão, afirmava ter sido vitimada por um "feitiço" que acarretava perda de peso e que seus pensamentos eram "controlados" por pessoas que desejavam que ela se tornasse progressivamente mais magra. Seu afeto tendia ao embotamento e seu humor não se encontrava polarizado. Desde o início do quadro, ganhou aproximadamente $15 \mathrm{~kg}$ (cerca de dois kg por mês) e, não obstante exibir peso acima do ideal, dizia enxergar a si própria como uma pessoa extremamente magra. Referia que o peso acima citado seria resultado de erros de mensuração, ou seja, que as balanças estariam "defeituosas".

Durante a internação, a paciente foi tratada com medicação antipsicótica, seguimento nutricional e atendimento psicoterápico de orientação cognitivo-comportamental. Uma vez que não apresentou resposta com monoterapia (haloperidol até $15 \mathrm{mg}$, risperidona até $8 \mathrm{mg}$ e ziprasidona até $160 \mathrm{mg}$ ), optou-se, por fim, pela associação de ziprasidona $160 \mathrm{mg}$ e risperidona $8 \mathrm{mg}$ ao dia. Houve melhora da sintomatologia psicótica e da hiperingesta alimentar, embora a paciente ainda mantivesse distorção da imagem corporal, crenças delirantes residuais (acreditava que as diversas balanças do hospital poderiam ter sido modificadas para indicar valores superiores aos reais quando de sua pesagem) e sobrepeso (manteve peso de $70 \mathrm{~kg}$, com índice de massa corporal $=28 \mathrm{Kg} / \mathrm{m}^{2}$, apesar de se encontrar sob acompanhamento nutricional). Recebeu alta após três meses de internação, sendo encaminhada para continuidade de seu tratamento em regime de hospital-dia.

A paciente em questão apresentava sintomas claramente compatíveis com o diagnóstico de esquizofrenia segundo os crité-rios do DSM-IV-TR. Concomitantemente, exibia clara sintomatologia relacionada a alterações da imagem corpórea e comportamento alimentar alterado. Estas alterações, embora sugestivas da presença de um transtorno alimentar comórbido, não possibilitaram que a paciente fosse considerada portadora de um transtorno desta natureza segundo as classificações psiquiátricas atuais. Casos semelhantes encontrados na literatura apontam para a existência de elementos comuns entre transtornos psicóticos, dismorfofobia e, possivelmente, um subgrupo de pacientes portadores de transtornos alimentares, gerando dificuldades de natureza nosológica e diagnóstica. ${ }^{1,3-}$ ${ }^{4}$ A literatura ainda é escassa no que se refere ao manejo de casos semelhantes e pouco se tem documentado sobre as possíveis abordagens terapêuticas. Por fim, cabe desta- 